\title{
Aproximaciones: hacia una política de la alteridad en la obra de Juan L. Ortiz
}

\author{
LAURA SOLEDAD ROMERO Universidad de Buenos Aires, Argentina / laurasoledadromero@gmail.com
}

\section{Resumen}

De modo muy esquemático, las lecturas críticas de la obra poética de Juan Laurentino Ortiz se dividen en dos grupos: uno, cuyo núcleo es la representación de la naturaleza, atiende a la relación fusional o mística entre el sujeto y el paisaje; el otro, cuyo núcleo es la realidad social, considera las dimensiones históricas y políticas. Nuestra hipótesis es que la obra de Ortiz reclama una reconsideración de las categorías políticas que subyacen a sus diferentes lecturas, a partir de una indagación del problema de la otredad como alteridad radical. En este sentido, el problema de la animalidad permite considerar una dimensión que escapa a la alternativa crítica. Los animales (así como otros entes no humanos) solicitan una consideración ética, pues plantean la relación entre el sujeto y el paisaje como tensión irresoluble que no puede desembocar en ninguna síntesis armónica. Reconsiderar el problema político a la luz de la ética implica conmover la dicotomía naturaleza/cultura y, en consecuencia, volver a plantear los términos para otra lectura política de esta obra que se sustraería a la dialéctica.

Palabras clave: poesía argentina / animalidad / desconstrucción / ética

\section{Approaches: towards a politics of alterity in the work of Juan L. Ortiz}

Abstract

In a very schematic way, the critical readings of the poetic work of Juan Laurentino Ortiz are divided into two groups: one, whose nucleus is the representation of nature, attends to the fusion or mystical relationship between the subject and the landscape; the other one, whose nucleus is social reality, considers the historical and political dimensions. Our hypothesis is that the Ortiz's work claim for a reconsideration of the political categories that underlie his different readings, based on an inquiry into the problem of otherness as a radical alterity. In this way, the problem of animality allows us to consider a dimension that escapes the critical alternative. Animals (as well as other non-human entities) request an ethical consideration, because they place the problem of the relation between the subject and the landscape as an unsolvable tension that can not lead to any harmonic synthesis. Reconsidering the political problem in the light of ethics implies shake the nature/culture dichotomy and, consequently, rethinking the terms for another political reading of this work that was removed from the dialectic.

Key words: Argentine poetry / animality /

deconstruction / ethics

Recibido: 25/4/2019. Aceptado: 31/7/2019

Para citar este artículo: Romero, L.S. (2019). Aproximaciones: hacia una política de la alteridad en la obra de Juan L. Ortiz. El taco en la brea, 10 (junio-noviembre), 17-27. Santa Fe, Argentina: UNL. DOI: 10.14409/ tb.v1i1o.8682 
De ahí también mi afición a los animales, o sea, el pre pensamiento — como se dice-, porque en ellos encuentro justamente lo que el hombre después, al organizarse de una determinada forma, se da a costa de toda esa fuerza.

Juan L. Ortiz, Una poesía del futuro

Martin Heidegger afirma que ciertos poetas requieren una conquista pensante (19): se trata de poetizar el pensamiento, estableciendo una intrínseca relación entre poesía y filosofía. Tal podría ser el caso de Juan Laurentino Ortiz. Como sugiere Daniel Freidemberg, tal vez se pueda hablar de una "filosofía orticiana» (81). Pero no se trata de aplicar categorías filosóficas para «explicar» la poesía de Ortiz, sino de considerar el pensamiento de su poesía tal como Heidegger lo hizo con Hölderlin. En efecto, ¿no han sugerido Hugo Gola y Juan José Saer que Ortiz es nuestro más grande poeta? ¿No ha sido colocada su obra «en el centro de la poesía argentina» (Prieto, 2005:114)? ¿Debe esta importancia ser motivo de una canonización y una momificación de museo o, más bien, ser considerada en su potencia de interrogación? Para nosotros, como en el Hörderlin de Heidegger, se trata de ir hacia una filosofía de la poesía.

En este sentido, basta con una primera lectura para percatarse de que la obra poética de Ortiz se halla habitada por múltiples y diversos seres. Es, justamente, en esa multiplicidad donde indagaremos; pues proponemos pensar los diversos modos de irrupción e inscripción de los animales a lo largo de toda su obra poética. Analizaremos dicha presencia desde los estudios de la animalidad, como problema que refiere a la alteridad radical, es decir, al otro más otro. Este problema implica interrogar los modos posibles de relación entre el viviente no humano y el viviente humano, aun cuando la aparición del otro anteceda todo supuesto de comunidad o mundo en común. Es desde ese habitar con-el-animal, creemos, que el ser-con-el-animal podría ser pensado como una cuestión de índole ético-política. Desde esta perspectiva, consideraremos una cierta insistencia comunitaria en la fragilidad de la hermandad que se plasma en las figuraciones de hombres y animales, pero también de otros seres como los niños y los ángeles. Se tratará entonces de «considerar al animal como el otro de las políticas de la alteridad con respecto al viviente no humano» (Cragnolini 2017:112).

A fin de repensar lo político en la obra del poeta entrerriano será pertinente relevar (desmontar) de qué modo la crítica literaria ha pensado la cuestión política en Ortiz y bajo qué supuestos se ha desarrollado tal lectura - desde luego, no sin diferencias y cesuras entre los críticos-. ' En líneas generales, dichos supuestos se exponen de manera dicotómica y encuentran una resolución al modo sintético. En esta lectura que supone una dialéctica se haya inscripta gran parte de la interpretación crítica. En contraste, en este trabajo atenderemos a la desconstrucción de la dicotomía naturaleza/política que divide la lectura entre: a) la consideración metafísica del existente en el mundo (correlativa de la consideración metapoética de la fusión entre el poeta y el paisaje) esto que podría ser entendida como una fusión a lo «oriental» en el sentido de la identidad sin mediación; b) la atención a los motivos sociales y políticos que ubican esta obra en la tradición de la poesía social argentina (es decir donde hay medición propia de Occidente, el pasaje, el movimiento que se da a través del discurso). En segundo lugar, comprenderemos la ética orticiana como una ética de la alteridad radical que solicita un replanteamiento del concepto de lo político y, en relación con esto, una transformación del modo de entender las relaciones entre poesía y 
política. Por último, y de manera preliminar, esbozaremos los lineamientos de lo que llamaremos la cuestión animal en la obra poética de Ortiz, a los fines de pensar de qué modo dicha cuestión puede ser re-elaborada desde una clave que Jacques Derrida esbozó como política heteronómica, es decir, una política que contemple la más radical alteridad: apertura que solicita pensar la poética orticiana como un hablar al otro y un abrirse a la llamada del otro (1989). En esta clave, no se tratará de una concepción «animista» de la naturaleza (Serra:43-56), sino de la palabra poética como vocativo que, renunciando a hablar del otro, lo interroga, lo solicita y, de modo correlativo, se deja solicitar como escucha.

\section{Una poesía difícil de clasificar}

Para Martín Prieto, la obra de Ortiz aparecía a mediados de siglo como inclasificable dentro las tradiciones de la poesía argentina. Ni modernista, ni posmodernista, ni vanguardista, ni sencillista, la obra orticiana desbordaba también el paisajismo y regionalismo característicos de la poesía entrerriana (2006:357-359). Sin embargo, tampoco esta poesía sería del todo asimilable a lo que Prieto denomina la tradición de la "poesía social» argentina, que comenzaría con la obra de Raúl González Tuñón (2005:117). Hugo Gola se refiere a la originalidad y a la soledad de esta obra, afirmando que no puede filiarse con ninguna tradición poética argentina (106). Para Sergio Delgado, esta singularidad se entiende en términos de autonomía literaria: refractaria a la publicación profesional y de circulación restringida, la poesía orticiana se escribe ajena a las escuelas o movimientos locales, en un retiro provinciano deliberado, con el horizonte de una obra total, de la cual cada libro forma parte (2004a:323-324).

Ortiz ha rehusado entonces las operaciones clasificatorias de las historias literarias. Esa dificultad clasificatoria vale también para la cuestión política. Pues ¿es la de Ortiz una poesía política? ¿Es una poesía social? Para ensayar una respuesta, es preciso establecer en qué términos la crítica ha definido la cuestión.

Dos parecen ser los temas que han predominado en la lectura de esta obra. Por un lado, la concepción de la naturaleza, en la que se interroga el vínculo entre el poeta y la belleza del paisaje como estado de armonía. Por el otro, la cuestión social y política, con sus motivos de la pobreza material, el comunismo militante de su autor y la filiación con la poesía social. Estos dos grandes ejes se piensan al modo de compartimentos estancos que solo a veces se encuentran. En última instancia, dichas dicotomías son subsidiarias de la distinción sujeto/objeto estructurante del pensamiento occidental. Esta relación se da siempre al modo dialéctico y, en consecuencia, concluye necesariamente su movimiento en un tercer elemento, «la conciliación» (donde todas las tensiones y los enfrentamientos han ido motorizando el proceso que deviene totalidad) ${ }^{2}$ que armoniza y/o fusiona lo que en las primeras instancias acontece de modo separado y opuesto. Creemos pertinente hacer una segunda diferenciación dentro de la distinción crítica que proponemos y alentada por las mismas lecturas de corte hegeliano. Dijimos anteriormente que el pensamiento dicotómico estructurante del mundo occidental es el presupuesto para pensar la primera «separación» en la obra, esto es: naturaleza/política, naturaleza/cultura (si lo entendemos como el proceso de transformación operado por los hombres). Sin embargo, cabe advertir que las lecturas de corte «místico» en torno a una naturaleza que se fusiona con el poeta, podrían ser leídas como una mimética con lo natural y anular así la diferencia; en ese sentido, coinciden con una vertiente «oriental» de pensamiento. En cambio, ya que la política es esencialmente mediación, estaría 
involucrado otro modo de pensar, lógico, dialéctico, occidental. Ahora bien, lo curioso es que tanto la naturaleza como la cuestión social/política también tendrán a su vez un nuevo movimiento «dialéctico» que por momentos permitirá hermanarlas.

Alfredo Veiravé subraya un proceso simbiótico entre el poeta y la naturaleza, una comunión definitiva que permite la fusión (76, 84-85, 87 y 103-104). Edelweis Serra se refiere al «ritmo universal del cosmos perseguido por la palabra que funde lo objetivo y lo subjetivo, el yo y el no-yo» (56). Carlos Mastronardi remarca «la identificación del alma con la totalidad del cosmos» (citado por Veiravé:103-104). María Teresa Gramuglio, por su parte, enuncia los «aspectos esenciales de la estética y poética de Ortiz: la índole simbólica de la poesía, por la cual todo ella sería un impulso hacia la unidad y una verdadera búsqueda de lo absoluto» (2005:993). Gola destaca el empeño del poeta en la búsqueda de la armonía y la unidad (106). Para Roxana Páez, la cualidad sencillista e impresionista de esta poesía implica «una estética equilibrada entre realismo objetivista y subjetivismo» (8).

En la otra vertiente crítica, el abordaje de la cuestión social y política no deja de presentar reparos y problemas. Según Prieto, El alba sube y El ángel inclinado constituyen una poesía ligeramente social por sus asuntos y proyecciones; en ese sentido, Prieto recuerda la filiación con González Tuñón, uno de los poetas sociales argentinos emblemáticos. Sin embargo, lo que se entiende por «poesía social» en Argentina está asociado con ámbitos urbanos, mientras que en Ortiz predomina el paisaje natural (2005:117). Por ello, Ortiz revela su filiación con la poesía belga, especialmente con Maeterlinck, ya que se trata de una poesía que, al decir del propio autor, comprende lo social (político) ${ }^{3}$ con el paisaje:

La poesía belga era lo mejor que había y es riquísima con respecto a la francesa (...) sobre todo en ese sentido que entonces a mí más interesaba, es decir, en el sentido del paisaje, y por otro lado, en el sentido social, son cosas que parecen contradictorias, pero en ciertos poetas se daban sin choques, o en forma dialéctica si se quiere, o sea, aun chocándose llegaban a cohabitar, a darse, casi a hermanarse por momentos. (Aguirre:29)

De este modo, el propio poeta habilita cierta lectura dialéctica entre «paisaje» $\mathrm{y}$ «sentido social», dialéctica que intenta «hermanar» por momentos ambas cuestiones que, a priori, permanecen aparentemente separadas. Así es como las «proyecciones sociales» derivan del mismo paisaje, un paisaje que contempla el devenir del río, el paso de los pescadores, el deambular de los pobres: niños, ancianos. Pero también los animales que transitan, están y son-el-paisaje (mundo).

Como se sabe, en este paisaje predomina el componente fluvial, ${ }^{4}$ que Ortiz toma del imaginario geográfico entrerriano, pero también del imaginario de la poesía china. Es el río como un estarsituado en el aspecto geográfico-metafísico: se relaciona con el «yo» de modo cuasi paradigmático. Según Prieto, «en el caso de Ortiz, va a tender más a la fusión que al choque o al cruce: es en esa fusión en la que el paisaje va a tener algo que decir» (2005:116). De esta manera, Ortiz resolvería la ecuación poeta-paisaje de un modo que lo aleja de cualquier acercamiento folclórico y entiende la relación del poeta con su medio como fusional. En sintonía, Juan José Saer señala que «el paisaje no se limita a lo regional sino como una proyección de su percepción del mundo y de su concepción de la poesía» (1997:81-83).

Por todo ello, es necesario indagar la dicotomía que gran parte de la crítica suele leer entre el sujeto y el objeto con la resolución en términos de fusión con la naturaleza entendida como simbiosis: «Embrionariamente, Ortiz ya está frente a la que tal vez sea su mayor aspiración: fusionar 
los mundos objetivo y subjetivo en un poema, resolución ideológica que supondrá también una de tipo formal» (Prieto 2005:118). La afirmación arrastra una serie de supuestos que merecen ser interrogados. Por un lado, el pensamiento dicotómico, que presupone el modo dialéctico sin ponerlo en cuestión; por el otro, una resolución «ideológica» que supera la oposición, sin resto, esto es: unidad de la unidad y unidad de la diferencia. La lectura de la «fusión» (en sus distintos niveles) es una de las más persistentes en la crítica orticiana, pero de ella no se extrae ninguna consecuencia y a menudo no se consideran los presupuestos que implica.

\section{¿Es la poesía de Ortiz social?}

Daniel García Helder considera que, después de El agua y la noche (1933), libro de un «epicureísmo casi puro», un «impresionismo dominante» $\mathrm{y}$ «un estilo a la vez sencillo y preciosista» (132-133), se produce un "giro estético ideológico» (135), constatable en El alba sube (1933-1936), que acusa el impacto de la crisis económica y social de su época. Hasta entonces, los aspectos materialistas de la poesía de Ortiz «tendrían que ver menos con la historia en sentido estricto que con una forma combinada de sensualismo, sentimentalismo e idealismo, donde el contenido sentimental haría de filtro o mediación entre lo real, y lo ideal, la cosa y el símbolo, lo práctico y lo especulativo» (132133). Para Julia Miranda, la imbricación entre vanguardia poética y vanguardia política es legible en la obra de Ortiz, así como en la de otros poetas que le son contemporáneos, durante el período 1936-1939. Coincide con Helder en señalar que El agua y la noche propone una lírica pura sobre el paisaje, pero difiere en cuanto al momento en el que la política «irrumpe» en la poesía orticiana (2).

Agustín Alzari defiende la tesis de la poesía orticiana como perteneciente a la tradición de la poesía social argentina que habría emergido en torno al grupo de Boedo. A partir de una exhaustiva reconstrucción del entramado político, social y cultural de la intelectualidad de izquierda en las décadas del 30 y del 40, Alzari establece una filiación entre la obra orticiana en el período 1936-1946 («Como poeta, como narrador y como intelectual militante, nunca produjo tanto en tan poco tiempo» — 2016:10—) y la poesía social que le fue contemporánea. Para ello, reconstruye parte de la historia menos conocida de la lectura de esta obra: la inclusión de Ortiz hecha por Álvaro Yunque en 1943 en el grupo de los poetas comunistas llevada a cabo en su antología Poetas sociales en Argentina; la realizada por Héctor Agosti en En defensa del realismo de 1945; y la de Carlos Giordano en el capítulo de la Historia de la literatura argentina del CEAL en 1967. A partir de esta reconstrucción, Alzari defiende la tesis de una «original» poesía social, caracterizada por una preocupación ideológica identificable con una posición de izquierda, pero de la cual están ausentes el mundo del trabajo, la alienación y la explotación, por lo que se volvería imposible de asimilar a la estética oficial del Partido Comunista. Indetectables en El ángel inclinado, los temas sociales «ingresan» a la poesía de Ortiz en la década del 30: lo que antes era una poesía lírica en torno a la armonía del paisaje entrerriano, sin no obstante abandonar este tópico constitutivo, va incorporando los temas de la injusticia social y la pobreza material del hombre desposeído.

Por su parte, Saer describe la autonomía de la obra de Ortiz con una lógica interna que lo mantuvo alejado de los eslóganes y del mercado editorial (80). En sintonía con este modo de la autonomía poética, Saer agrega en el film Homenaje a Juan L. Ortiz de Marilyn Contardi (1994) que las preocupaciones sociales en la poesía de Ortiz están perfectamente alejadas de los «discursos declamatorios y meros eslóganes políticos a los que nos han habituado los así llamados poetas comprometidos». 
Gramuglio parece querer suturar estas dos vertientes críticas describiendo tres movimientos: la dicha, figurada en la integración armónica del poeta y el paisaje natural; la irrupción de la injusticia social que corroe esa armonía; y el anhelo de un orden superador en el que la contradicción quede disuelta (2004:56). Para Beatriz Sarlo, los temas sociales son el gran «riesgo» que enfrenta la poesía de Ortiz, porque se trata de una materia marcada por el sentimentalismo y el humanismo, lo que amenaza al poema con «precipitarse en lo obvio» (274). Por su parte, Freidemberg señala que Ortiz nunca concibió la poesía como un instrumento de lucha ni la subordinó a un fin político y, si bien aparecen temas políticos, aunque escasamente, son siempre integrados en un sistema más «vasto» 0 «esencial» (84-85).

\section{¿Es la poesía de Ortiz política?}

Con esta pregunta, empezamos a deslindar nuestra propia posición. Hasta aquí hemos dejado que conteste la crítica, limitándonos a examinar sus supuestos. Hemos visto que las nociones de lo político y lo social se solapan, se superponen parcialmente y se confunden. La obra de Ortiz se ubica en la tradición de la poesía social, aunque siempre con salvedades: es «original» en esa tradición o solamente le pertenece en algunas de sus etapas. La pregunta por lo político solo se plantea en relación con esta problemática. La poesía social es el modo en el que en la obra puede reconocerse una posición política identificable como de izquierda. Incluso el intento de Gramuglio de suturar las dos vertientes de la crítica parece presuponer esta aspiración utópica en la que la revolución es la instancia de superación de la oposición naturaleza/política.

Es necesario, en consecuencia, replantear los términos de la relación entre literatura y política. La crítica orticiana parece considerar lo político en términos representativos, es decir, como macropolítica (Deleuze y Guattari:28-44). Este presupuesto no es ajeno a la dificultad de separar la obra poética del «personaje» del poeta, aunque muchos críticos defiendan el carácter autónomo de la obra. Para pensar la política en su poética, hay que considerar otro concepto de política. Si la palabra orticiana ha sido descrita por la crítica como leve, murmurante, interrogante y cercana al silencio, esta condición no puede reducirse a lo rítmico verbal o a la armonía en la representación del paisaje natural: la delicadeza orticiana (relacionada además con el sensualismo de la poesía en lengua francesa y con el orientalismo) estaría sugiriendo algo acerca del poder.

Replantear la interrogación por lo político implica también volver a preguntarnos qué es la literatura y, en el caso de Ortiz, qué es la poesía, pues tal vez la concepción orticiana misma permita pensar otra relación a partir de la experiencia de un cierto im-poder: «la literatura no está al servicio de ningún poder; al contrario, es como dijimos, la destitución de todos los poderes y de la noción misma de poder: una afirmación que no es un poder» (Cueto:4). En consecuencia, la relación entre poesía y política debe plantearse a partir de la primera. Para la crítica, la poesía orticiana parece relacionarse con la política por la mediación dialéctica de lo social (o incluso de la poesía social). Puede oponerse a esta concepción la afirmación de una poesía orticiana inmediatamente política. En efecto, aquí también la dialéctica, que rechazamos, juega su papel. Pues la diferencia entre macropolítica y micropolítica es que mientras la primera implica siempre una búsqueda de la toma de un poder (incluso cuando esa aspiración es la reivindicación de una marginalidad o un colectivo oprimido), la segunda es siempre un devenir: no busca la toma de ningún poder, sino la destitución de todo poder establecido. Las luchas macropolíticas son dialécticas en este sentido. La micropolítica es la puesta en devenir continua de toda posición estática: «De allí que el devenir, la fuerza 
propiamente micropolítica, sea inasimilable a ningún poder macropolítico» (Cueto:5). En consecuencia, hay que preguntar: ¿cuál es la naturaleza micropolítica de la fuerza poética orticiana?

\section{Hacia un «entre» tensional}

Ahora bien, una serie de trabajos críticos permiten problematizar este clivaje entre dos modos de leer inconmensurables o conciliables solo de modo dialéctico. Es en torno al concepto de «mundo», de raigambre heideggeriana, que el trabajo de Héctor Píccoli y Roberto Retamoso contribuye a la desconstrucción de estas dicotomías estructurantes que dividen la lectura de Ortiz. Píccoli y Retamoso parten de la consideración de esta poesía en relación con el éxtasis y en relación con el misticismo. En cuanto al primero, la arquitectura del poema orticiano organiza una enunciación reflexiva que impide la separación neta entre sujeto y objeto: «el recurso a la reflexividad permite configurar un juego constante, una oscilación bipolar, entre el estar "en sí" y el estar "fuera de sí", entre el ser y el dejar de ser para ser en el otro» (173). En relación con el misticismo, se trata de la comunión con el mundo: aquí también Píccoli y Retamoso eluden la dicotomía sujeto/objeto, considerando la compenetración del discurso y el mundo que plantea el lenguaje poético (174). En este contexto, «mundo» conlleva la idea de un conjunto incluyente, organizado como totalidad significante, y es irreductible a la idea de realidad, fuere natural o social: en esa totalidad, los elementos remiten unos a otros, están en relación de co-referencialidad (175). La naturaleza es, en consecuencia, solo una parte del mundo, al igual que el hombre, que carece en esta organización de todo privilegio: el mundo es una totalidad autoconsciente de sí misma. Esta totalidad mundanal es aquello que el hombre debe conquistar, pues su «en sí» enajenante, su «incomprensión», tienen como consecuencia la crueldad en cuyo origen se sitúan los males más inmediatos (o materiales) como la injusticia, la pobreza y el hambre, y los más «sutiles» como la falta de realización de todas las potencialidades del espíritu. Para Píccoli y Retamoso, el ejemplo más patente de esta incomprensión (pero no es un mero ejemplo) es la crueldad hacia lo viviente no humano que llamamos «animal», sea como concepto biológico materialista que excluye lo espiritual (el desprecio por la parte animal del hombre), sea como esos «otros» a los que se reduce en la crueldad:

La desmesura de la crueldad no tiene atenuantes, ni siquiera la «alimentación» es un pretexto válido: criar para matar e incorporar — comer - no es, no debe ser, en absoluto "necesario». Por el contrario, es dable imaginar un estadio — quizás aún lejanísimo— en el que hombre, bestias y reino vegetal convivan. (1986:178)

Por otro lado, Cleila Moure advierte el uso casi irresponsable de este pretendido concepto de «fusión» (presupuesto que compartirían Veiravé, Mastronardi y Prieto); en este sentido, afirma: «no me parece que la relación entre sujeto poético y mundo evocado pueda concebirse aquí según las alternativas de un esquema binario (la fusión sigue a la separación, y por lo tanto es tributaria de un esquema conceptual binario y, por fuerza, dicotómico)» (366). Contrariamente, la crítica propone una «singular tensión» que elude cualquier tipo fusional entre el sujeto y el mundo. Ataca, además, la sostenida dicotomía sujeto/objeto y advierte que no es viable pensar en términos que presupongan una resolución de tipo armónico, simbiótico o fusional, sino que más bien se trata de re-pensar la dicotomía, pues de otro modo la incertidumbre, el vacío y la intemperie que habitan la obra de Ortiz serían acallados y reducidos por la lógica dialéctica: se trata entonces de desentrañar la «tensión» de cierto «sujeto» con el mundo (366). 
Para Delfina Muschietti, el yo subjetivo se disuelve en pos de una voz colectiva e impersonal y «poeta y paisaje, sujeto y objeto, se conectan» (23) y, posteriormente, «ya no hay sujeto ni objeto sino devenir impersonal» (29). En esta línea, Mónica Cragnolini realiza una lectura en clave nietzscheana de la obra en prosa de Ortiz. La filósofa sugiere que se la ha interpretado, sobre todo la poesía, como una búsqueda de la totalidad y el absoluto. En contraste, propone una lectura del paisaje que dé cuenta del «entre», del «estar en» el paisaje, más que de fusión con el mismo (165-171). De este modo, el «entre» el animal y el hombre, esa hermandad de la fragilidad, es el de las fuerzas que atraviesan a hombres y bestias.

\section{Hacia una política de la alteridad radical}

La pregunta por la cuestión política en la poesía orticiana derivó en un radical cuestionamiento de los supuestos que estructuran las lecturas políticas críticas. De allí la posibilidad de poner en evidencia el pensamiento dicotómico en torno al sujeto/objeto y, a partir de ciertos críticos, plantear una lectura que recoja el carácter impersonal y la tensión insalvable e irresoluta de todo aquello que escapa a una subjetividad fuerte. Desde los márgenes, proponemos pensar de modo ético-político todo aquello que en la poética orticiana se presenta de manera susurrante, frágil, no-humana.

Ahora bien, ¿por qué no pensar la relación directamente desde la ética? Oscar del Barco considera la relación entre poesía y ética en la cual la obra de Ortiz se presenta como paradigmática. ${ }^{5}$ Es interesante que el animal, en esta lectura, aparece como «otro»: su interpretación de «otro modo de ser» suscribe el pensamiento ético de Emanuel Lévinas. Así como Lévinas sostiene el hiato entre ética y política que se plenifica con un contenido deudor de lo teológico-político, de modo similar Del Barco desplaza la cuestión política y pone el acento en la relación entre poesía y ética: «Esta indefensión de la poesía constituye lo imposible de la política, o es lo que toda política debe desplazar para poder realizarse como política» (2015:112). La afirmación supone una concepción predominante de lo político como «voluntad de poder» (Del Barco, 2008:203), es decir, presupone el concepto clásico de soberanía. Ahora bien, para Levinas, a un animal, en tanto ente dentro del horizonte del ser, no se lo asesina, sino que se lo caza o se lo abate, quedando así excluido radicalmente de la esfera ética del no matarás. ${ }^{6}$ Llama entonces la atención que Del Barco apele a Levinas y simultáneamente atienda a la cuestión animal en Ortiz.

Una de las notas características de esta posición ante la vida no-humana reside en negarle la posibilidad del lenguaje, reducirlo al lugar del silencio o la phoné ajena al logos. Es por ello que incluso un pensamiento tan sensible a la otredad como el levinasiano es incluido por Derrida en la tradición carno-logo-falocéntrica. Como señala Derrida refiriéndose al modo en que Adorno aborda la problemática del dominio sobre la naturaleza, «el fascismo comienza cuando se insulta a un animal, incluso al animal en el hombre» (2004:37). Muestra así lo decisivo de la palabra y el lugar que se le asigna al animal, pues allí se juega el principio sobre el que se construye una política (Chun). De modo que no se tratará de esperar la respuesta sino de atender a la escucha.

Nos pararemos entonces en el terreno de la desconstrucción, valga el carácter paradójico de tal afirmación, para pensar junto con Derrida un modo de lo político que quiebre con los conceptos heredados de la tradición. Esbozaremos así una posible articulación para una política que no traicione la ética de la alteridad radical levinasiana. El pensamiento político derridiano nos conmina a hacer temblar todo suelo firme sobre el que construir diferencias jerarquizantes que culminan, siempre, 
en políticas sacrificiales. Las políticas posibles de la soberanía se basan en una economía sacrificial que se devora al otro (Derrida, 1989) y más aún en el seno mismo de la consideración del «sujeto». Jean-Luc Nancy señala que «la vida del sujeto —o lo que Hegel llama la vida del Espíritu— es la vida que vive de sacrificarse» (55). Ahora bien, la desconstrucción del concepto de soberanía pone en cuestión la distancia que se pretende mantener con relación al principal objeto de dominio: la vida no-humana. Como señala Derrida: «No se trata, evidentemente, de ignorar o borrar todo lo que separa a los hombres de los otros animales» (2008:65), pues estamos pensando justamente en espacios atravesados por la diferencia (différance). En este sentido, todo el esfuerzo de Derrida está dirigido a señalar el carácter ficticio, múltiple, permeable y heterogéneo de cualquier frontera, en este caso aquella que se da entre el hombre y el animal. No se pretende entonces borrar las diferencias, las distancias, sino plantear que todo intento de límite no puede ser nunca estable, preciso, unívoco; al mismo tiempo, la desconstrucción desenmascara los límites como simulacros (Chun). Pero, como ha demostrado la historia de la «humanidad», estos límites resultan en injusticias hacia las posibles alteridades; entonces, las consecuencias de tales fronteras operan generando sus propias víctimas.

Si retomamos todos los hilos críticos, comprobamos que la idea de «armonía universal» es el presupuesto común tanto a la lectura «metafísica» que se detiene en la contemplación del paisaje como a la idea de una "comunidad política» (fraternidad, paz, igualdad) en la que el dolor y la violencia encontrarían una solución. Para nosotros, la consideración ética implica un dolor y una violencia originarios en tanto la apertura al otro conlleva un riesgo y una asimetría. Si para Levinas la ética es, sin más, la ontología (y tanto Del Barco como Derrida retoman la ética levinasiana), esto significa que la desgarradura que me separa del otro pertenece a la estructura ontológica del existente. Para la poesía de Ortiz, la muerte del perro y la pobreza del niño son figuras de la desposesión y de la precariedad al mismo tiempo ontológicas y políticas: la muerte es la experiencia de que la naturaleza es dolorosa y violenta, así como la utopía es la idea de que la cultura humana puede ser armónica. Considerar la política solo en términos de comunidad armónica reintroduce el desconocimiento de la alteridad cuando pretende erigirse en ética, pues esa comunidad está basada en la semejanza. La consideración ético-política que para nosotros plantean las distintas figuras de la otredad en la poesía orticiana (niños, pobres, animales, bestias, ángeles) se situaría en el tránsito del quién al qué: «algo (un que) resiste: el resto. El otro viviente (animal, humano) es lo que, a pesar de todos los intentos devoradores, no puede ser apropiado, el que intraducible al quien, el que indigerible» (Cragnolini, 2011:317). Es decir, en la desconstrucción de la noción misma de sujeto en tanto se relaciona con el otro en virtud de esta semejanza (y es en este punto que la heteropolítica derridiana absorbe y desborda la ética levinasiana). Por el contrario, acoger al otro no como semejante, sino como alteridad radical, implica considerar no un quién antropomorfo, sino un qué indeterminado y absolutamente extraño: «Un principio de ética (...) es quizás la obligación que compromete mi responsabilidad con lo más desemejante, con lo radicalmente otro, justamente, con lo monstruosamente otro, con lo incognoscible» (Derrida, 2010:139).

Esta política heterológica no sería un regreso sin más a la ética, pues es inseparable de la «justicia» como la entiende Derrida, noción que debe ser pensada como diferente del «derecho»: el derecho está concebido a partir de la semejanza y de lo calculable, se funda en un concepto de soberanía humana; la justicia, por su parte, excede lo humano y acoge lo absolutamente heterogéneo: es del orden de lo desemejante, es exposición incalculable al otro, es disponibilidad a la alteridad radical y espera del acontecimiento. 
Nuestra propuesta se sitúa entonces en el clivaje que deslinda ética de política para considerar cómo la primera puede conmover los supuestos metafísicos de la segunda, lo que permitiría hablar de una heteropolítica o una hiperpolítica (Derrida, 2005), una política heteronómica que desdibuje los límites entre lo ético y lo político: «Hay en este pensamiento [el de Derrida] algo que podría ser llamado un desbordamiento ético de lo político, es decir, un planteamiento que excede lo que tradicionalmente se atribuyó de suyo a lo político en virtud de la introducción de la dimensión ética» (Llevadot:522). Se tratará entonces de pensar otro concepto de lo político que halle en la alteridad su condición; solo así podrá atenderse a aquello que susurra en la obra orticiana.

\section{Notas}

1 Aclaro que no estoy considerando las llamadas «etapas» en la obra de Ortiz, porque mi intento de lectura, aunque no totalizador, pretende ser abarcativo, entendiendo que la animalidad atraviesa la poética del autor.

2 El planteo hegeliano se condice en parte con esto: si en el primer momento lo que prevalece es la unidad sin diferencia, y en el segundo la diferencia, el choque, la alienación, la oposición, el tercer momento, resolutivo de esta dinámica, es aquel que acoge dentro de sí a los dos anteriores, y se presenta como unidad de la unidad y de la diferencia.

3 La confusión entre «social» y "político» es un problema intrínseco a las mismas lecturas críticas. Frecuentemente las dos palabas parecen sinónimos. Se distancian eventualmente cuando lo político refiere a cuestiones de índole partidaria y lo social a una vaga preocupación ético-moral por los marginales, oprimidos y pobres del mundo.

4 Para otra lectura de lo fluvial en la poesía de Ortiz, ver el excelente estudio (Delgado, 2004b:7-54).

5 Un análisis pormenorizado de la lectura filosófica de Del Barco sobre la relación ética y poesía nos llevaría en una dirección que desborda ampliamente los límites de este trabajo. Aquí nos limitaremos a indagarlo desde una crítica de la ética levinasiana que repele todo análisis de lo político y, en consecuencia, la exclusión de la consideración política de la animalidad.

6 Para un trabajo pormenorizado de la cuestión política en relación con la animalidad, cfr. Chun.

7 Para un examen de la tradición filosófica que excluyó al animal, cfr. Derrida (2008).

\section{Referencias bibliográficas}

Aguirre, 0. (Comp.) (2016). Una poesía del fututo. Conversaciones con Juan L. Ortiz. Buenos Aires: Mansalva.

Alzari, A. (2016). La poesía social de Juan L. Ortiz (1936-1946). Tesis Doctoral. http://www.memoria.fahce. unlp.edu.ar/library?a=d\&c=tesis\&d=Jte1263

Contardi, M. (1994). Homenaje a Juan L. Ortiz. Film.

Cragnolini, M. (2009). Brevísimas notas sobre animales y niños en Juan L. Ortiz y en Nietzsche. En Instantes y Azares. Escrituras nietzscheanas, Vol. VII, Buenos Aires, 165-171.

(2011). Hospitalidad (con el) animal. En Escritura e imagen, Vol. ext., 313-324.

(2017). Política de la otredad: la cuestión animal. En Dei, D. y Divenosa, M.G. (Ed.), La cuestión del otro en la filosofía, la política, la sociedad y la cultura. Universidad Nacional de Lanús: H. Argentina.

Cueto, S. (1993). Notas para una política de la literatura. Boletín/3 del Centro de Teoría y Crítica Literaria. Rosario.

Chun, S. (2016). Política y ética en el pensamiento de Jaques Derrida. Tesis Doctoral. http://repositorio.filo. uba.ar/handle/filodigital/4101?show=full 
Del Barco, O. (2008). Consideraciones sobre un poema de Juan L. Ortiz. En La intemperie sin fin. Córdoba: Alción, 193-206.

(2015). Juan L. Ortiz. Poesía y Ética. Córdoba: Alción.

Deleuze, G. y Guattari, F. (1978). Kafka. Por una literatura menor. México: Era.

Delgado, S. (2004a). El aura de Juan L. Ortiz: la autonomía y los poetas. En Jitrik, N. (Ed.). Historia Crítica de la Literatura Argentina. Tomo 9, Saítta, S. (Coord.). El oficio se afirma. Buenos Aires: Emecé. (2004b). El río interior (Estudio preliminar). En Ortiz, J.L. El Gualeguay. Rosario: Beatriz Viterbo, 7-54.

Derrida, J. (1989). Il faut bien manger ou le calcul du sujet., entretien avec Jean-Luc Nancy. Cahiers Confrontation. París, $\mathrm{N}^{\circ} 20$.

- (2003). Como si fuese posible. «Within such limits». En Papel máquina. Madrid: Trotta. (2004). Acabados seguido de Kant, el judío, el alemán. Discours de Francfort. Madrid: Trotta. Traducción de Patricio Peñalver.

- (2005). Canallas. Dos ensayos sobre la razón. Madrid: Trotta.

- (2008). El animal que luego estoy si(gui)endo. Madrid: Trotta. (2010). Seminario La Bestia y el Soberano Vol. I. Buenos Aires: Bordes Manantial.

Freidemberg, D. (2001). Reververaciones, llamados, misterios: Juan L. Ortiz. Inti, 79-98.

García Helder, D. (2007). Aspectos materialistas en la poesía argentina. Cuadernos LIRICO, (3), 131-148.

Gola, H. (2005). El reino de la poesía. En Ortiz, J.L. Obra completa. Santa Fe: Universidad Nacional del Litoral, 105-110.

Gramuglio, M.T. (2004). Juan L. Ortiz, maestro secreto de la poesía argentina. Cuadernos Hispanoamericanos, 45-65. (2005). Las Prosas del poeta. En Ortiz, J.L. Obra completa. Santa Fe: Universidad Nacional del Litoral, 989-994.

Heidegger, M. (2010). Los himnos de Hölderlin «Germania» y «El Rin». Buenos Aires: Biblios.

Llevadot, L. (2013). No hay mundo común: Jacques Derrida y la idea de comunidad. ISEGORÍA. Revista de Filosofía Moral y Política, (49), 549-566.

Miranda, J. (2009). La escritura política en Juan L. Ortiz. Un comienzo borrado. En Actas del II Congreso Internacional Cuestiones Críticas. Rosario.

Moure, C. (2005). La ausencia de la dicotomía sujeto-objeto en la poesía de Juan L. Ortiz. En Cuadernos para investigación de la literatura hispánica, (30), 365-378.

Muschietti, D. (2004). Juan L. Ortiz, barroco de la levedad. En Hispanic poetry review, 4(1), 1-36.

Nancy, J.-L. (2002). Lo insacrificable. En Un pensamiento finito. Barcelona: Anthropos. Traducción de Juan Carlos Moreno Romo.

Páez, R. (1997). Juan L. Ortiz: primeros diálogos. Orbis Tertius, 4(2), 1-9.

Píccoli, H. y Retamoso, R. (1986). Juan L. Ortiz. En Zanetti, S. (Dir.). Capítulo. Historia de la literatura argentina. Buenos Aires: CEAL.

Prieto, M. (2005). En el aura del sauce en el centro de una historia de la poesía argentina. En Ortiz, J.L. Obra completa. Santa Fe: Universidad Nacional del Litoral, 111-125.

(2006). Breve historia de la literatura argentina. Buenos Aires: Taurus.

Saer, J.J. (1997). Juan. En El concepto de ficción. Buenos Aires: Seix Barral.

Sarlo, B. (2007). Juan L. Ortiz. En Saítta, S. (Ed.). Escritos sobre literatura argentina. Buenos Aires: Siglo XXI.

Serra, E. (1976). El cosmos de la palabra. Mensaje poético y estilo de Juan L. Ortiz. Buenos Aires: Noe.

Veiravé, A. (1984). Juan L. Ortiz. La experiencia poética. Buenos Aires: Carlos Lohlé. 